Geografia e Ordenamento do Território, Revista Eletrónica

Centro de Estudos de Geografia e Ordenamento do Território

CEGOT

Centro de Estudos de Geografia e Ordenamento do Território http://cegot.org

ISSN: 2182-1267

Marques, J.

CEGOT, Faculdade de Letras da Universidade de Coimbra

jorgehsm@sapo.pt

\title{
Trabalho, Lazer e Turismo de Negócios
}

Referência: Marques, J. (2012). Trabalho, lazer e turismo de negócios. Revista de Geografia e Ordenamento do Território, n. 2 (Dezembro). Centro de Estudos de Geografia e Ordenamento do Território. Pág. 139 a 163

\section{Resumo}

As viagens motivadas pelos negócios e profissões referem-se a uma das mais antigas formas de viajar, tendo a sua evolução ocorrido ao longo dos tempos à medida que as sociedades se foram transformando económica e socialmente. Hoje em dia, não só falamos de viagens de negócios como também de Turismo de Negócios que, para muitos destinos, representa um importante setor económico. Com este trabalho pretende-se fazer uma breve análise à evolução dos conceitos de trabalho, lazer e viagens de negócios ao longo dos últimos séculos, de modo a melhor compreendermos este fenómeno relativamente recente.

Palavras-chave: Trabalho, lazer, viagens de negócios, turismo de negócios 


\section{Abstract}

The trips motivated by business and professions refer to one of the oldest forms of travel, and its evolution occurred over time as societies have been transformed economically and socially. Today, we refer not only to business travel but also to business tourism that for many destinations represents an important economic setor. With this work we intend to make a brief analysis of the evolution of concepts of work, leisure and business travel over the past centuries, in order to better understand this relatively recent phenomenon.

Keywords: Work, leisure, business travel, business tourism 


\section{Trabalho, tempo livre e lazer}

Os valores que o tempo de trabalho, o tempo livre e as práticas de lazer assumem podem ser diversas, dependendo das motivações pessoais de cada indivíduo, do tipo de emprego que possuem, do estilo de vida que adotam, dos espaços e dos lugares onde se desenvolvem. Como referem Gama \& Santos (2008,pp. 62-63), “ $a$ terciarização da sociedade moderna tem sido acompanhada pela modificação de sentido das concepções de trabalho, tempo livre e lazer e, em consequência, das suas fronteiras respetivas. À oposição lazer/trabalho, que foi consoante as épocas e os lugares, de uma valoração positivo/negativo, sucede, nas sociedades pós-industriais, uma modificação crescente do sentido dos termos, não mais redutíveis às dicotomias anteriores. O tempo livre não significa necessariamente ócio ou lazer, assim como trabalho pode ser, em muitos casos, sobreponível ou mesmo confundido com estados ou práticas de lazer." Por um lado, porque na própria conceptualização de tempo de trabalho podemos conceber a existência de tempos livres; por outro, porque dentro do tempo livre podemos distinguir tempos coercivos, ou tempos que não são

verdadeiramente livres. Podemos considerar inclusivamente que nem sempre a diminuição do tempo de trabalho origina o aumento de tempo verdadeiramente livre, tendo em conta, por exemplo, que as tarefas domésticas do quotidiano apesar de se inserirem num tempo livre do tempo formal de trabalho (emprego), não deixam de ser coercivas. O mesmo se verifica nas situações de desemprego ou através de horários laborais mais reduzidos/repartidos, onde o aumento do tempo de não trabalho pode resultar na procura de outras ocupações como forma de obtenção de maior rendimento. Por outro lado, certas profissões implicam vivências fora dos locais habituais de residência, como é o caso das viagens de negócios, e podem incluir, num tempo global que é considerado tempo de trabalho, diferentes frações de tempos livres ou tempos de lazeres. Do mesmo modo, e apesar de todas as transformações conceptuais e ideológicas, ainda podemos constatar que em alguns casos específicos o lazer encontra-se intimamente ligado à sociologia do trabalho. Veja-se o caso das viagens de incentivo, inseridas na esfera do Turismo de Negócios, que têm como 
objetivo a recompensa ou motivação dos trabalhadores/colaboradores das empresas, podendo ser considerado este fenómeno como uma forma moderna de "reposição da força bruta de trabalho".

\section{Da evolução do tempo livre à valoração do lazer}

As transformações ocorridas ao longo dos últimos séculos, como por exemplo, as progressivas reduções do tempo de trabalho e consequente aumento do tempo livre, a conquista do direito às férias pagas, o aumento da esperança média de vida, a antecipação da idade de reforma, o desenvolvimento dos meios de transporte e das comunicações, o aumento da inserção da mulher no mercado de trabalho e o desenvolvimento do consumo massificado (refletindo, consequentemente, o aumento do consumo das práticas de lazer), foram alguns dos fatores que contribuíram para a construção de sucessivas análises à problemática do tempo livre e do lazer.

O estatuto de ociosidade que algumas classes detinham até ao advento da revolução económica e político-social desencadeada no século XVIII foi sucessivamente desconjuntado, assumindo o trabalho um papel central na valorização moral e social do homem, no decurso de um processo que se desenvolveu pelo menos desde o século XIX e que corporizou as teorias económicas prevalecentes (Martins, 2004). A partir daqui, verificou-se o ressurgimento do lazer como uma necessidade para manter os níveis elevados da produção industrial e, já no século $X X$, como uma justa recompensa para quem trabalha, evidenciando-se, a partir das décadas de 60 e 70 até à atualidade, como valor social, de produção e de consumo (Santos, 2011; Lipovestky, 2006; Nazareth, 2007; Sue, 1982; Martins, 2004), onde a um maior tempo livre corresponde geralmente um maior consumo (Pizzorno, 1956 citado por Gama, 2008a).

Apesar de haver quem considere que o lazer sempre existiu em todas as épocas e todas as civilizações (Sebastien de Grazia, Of Time, Work and Leisure de 1956; Georges Hourdin, Pour une civilisation des loisirs, 1961, entre outros), o conceito de lazer, tal como o conhecemos hoje em dia, surgiu na era industrial. "Se é bem verdade que o tempo de trabalho é tão antigo como o tempo fora do trabalho, já o lazer apresenta 
traços específicos característicos da civilização nascida da revolução industrial" (Dumazedier, 2002, p. 148).

Nas civilizações primitivas, de características predominantemente agrárias, a relação tempo de trabalho/tempo livre não conhecia fronteiras claras. O tempo de trabalho era imposto pelos ciclos climáticos e, consequentemente, o tempo livre daí subsequente, também ele era coercivo. Já na Antiguidade Clássica, o tempo livre assume um caráter ocioso, característico de classes, evidenciando-se uma separação social entre as classes trabalhadoras e as classes ociosas que viam o trabalho de uma forma negativa, e onde apenas aqueles que pertencessem a determinada "casta" é que poderiam gozar do estado de ociosidade (Sue, 1982). "Nas sociedades préindustriais, de organização feudal, no mundo muçulmano e noutrem do oriente, encontra-se a mesma clivagem entre uma classe ociosa, que gasta o seu tempo no ócio, e a grande massa de servos dedicados ao trabalho" (Gama, 2008a, p. 91). Para estes, o tempo livre do tempo de trabalho era, na verdade, um tempo imposto pelas ritualizações religiosas e pelas contingências climáticas (Sue, 1982), enquanto para as classes ociosas o tempo livre assumia um papel de substituto do tempo de trabalho, por direito de classe. A ociosidade assume, neste contexto, um papel de substituto do trabalho e não um complemento ou compensação do tempo de trabalho. Com o abandono das estruturas feudais e o surgimento da sociedade capitalista surgiram também novas formas de divisão do tempo e novas perspetivas sobre o tempo dedicado ao trabalho e ao ócio. O desenvolvimento do comércio e o aumento na produção de bens, as Grandes Navegações e as Reformas de Lutero e Calvino levam as sociedades a valorizarem moralmente o trabalho e a desvalorizarem o tempo dedicado ao ócio (Bacal, 2003), ideologia que se afirma com a Revolução Industrial e com alguns pensadores do século XIX. A este respeito, Smith e Saint-Simon encaram a sociedade do século XIX como uma sociedade de produção e condenam o ócio devido ao seu caráter não produtivo e socialmente ineficaz. Na Parábola de Saint-Simon, a nobreza é descrita como uma classe ociosa e, por isso, socialmente inútil, ao contrário das classes trabalhadoras e da burguesia nas quais as virtudes do trabalho são enaltecidas. A mentalidade associada à moral do trabalho encontra-se enraizada nas ideologias e nas ações políticas, onde o tempo livre de trabalho exerce uma função primordial de 
repouso e recuperação física de modo a reestabelecer a força de trabalho (Gama, 2008a). Neste âmbito, Veblen faz uma análise ao lugar e ao valor da classe do ócio na América dos finais do século $\mathrm{XIX}$, criticando a sociedade do lucro e do regime capitalista e considerando a classe ociosa como uma classe consumidora de bens supérfluos e improdutiva, numa sociedade onde o ócio e o "consumo vicário" se assumem como fatores diferenciadores de classes (Veblen, 1965).

Em meados do século XIX nos estudos de Marx, mais precisamente na obra O Capital, onde aborda o trabalho como o primordial valor moral, denota-se especial atenção dada às práticas realizadas fora do tempo de trabalho como forma de valorização e realização pessoal e onde o divertimento e o desenvolvimento pessoal assumem um papel importante. Esta perspetiva foi desenvolvida por Paul Lafargue, genro de Marx, na obra $O$ Direito à Preguiça publicada pela primeira vez em 1880, onde defende que as classes trabalhistas também devem ter direito a um tempo de lazer e às práticas a ele associadas, como é o caso das artes, até então reservadas a uma classe burguesa que, por sua vez, destronou a nobreza na supremacia económica e política (Lafargue, 1991). Podemos considerar então que a partir desta altura o conceito de lazer surge de uma forma mais efetivamente presente. A partir dos finais do século XIX e inícios do século $\mathrm{XX}$, até aos anos trinta, o desenvolvimento do capitalismo industrial e as lutas sociais que o acompanharam vieram trazer uma revalorização do tempo dedicado ao lazer (Gama, 2008a). Como refere Lefèbvre, a evolução da organização do trabalho industrial levou à valorização do tempo livre e do lazer, diferenciando-se das formas como é tomado nas sociedades tradicionais, e onde as "fadigas da vida moderna tornam indispensáveis o divertimento, a distração, o descanso" (Lefèbvre, 1968, p. 103, citado por Gama 2008b, p. 18). A redução do tempo de trabalho e o reconhecimento do direito ao lazer pelas classes trabalhadoras levou a que alguns autores se referissem a esta sociedade como a que deu origem à civilização dos lazeres (Dumazedier, 1962; Touraine, 1969), generalizando-se o seu acesso a todas as classes, criando a ilusória ideia de igualdade social. Ilusória porque nessa altura, tal como na atualidade, as práticas de lazer funcionam também como fator de segregação social, onde um maior poder de compra permite o acesso a lazeres mais diferenciados ou restritos, em diferentes espaços, durante mais tempo e num maior número de vezes. 
Com o desenrolar do século XX a análise das estruturas socioeconómicas dá cada vez mais expressão ao estudo dos temas do lazer e dos tempos livres levando ao surgimento de duas correntes de pensamento principais. Por um lado, uma corrente de base socialista impulsionada pelos movimentos político-sociais dos países da Europa de leste, que analisa o lazer subordinado ao tempo livre, à sua produção, evolução e conteúdo (Gama, 2008a); Por outro, uma corrente de base capitalista que analisa o lazer subordinado ao trabalho, dando origem à autonomização do estudo do lazer e a uma crescente atenção aos aspetos do consumo. Friedman foi um dos principais autores a destacar-se na área da sociologia do trabalho e na análise da problemática tempo de trabalho/tempo livre. Considerado por Dumazedier como o "primeiro sociólogo francês a sublinhar o papel capital do lazer na humanização da civilização técnica" (Dumazedier, 1962, p. 79), num dos seus estudos dedicou-se à análise dos efeitos nefastos do trabalho mecanizado e repetitivo no comportamento, que geram sentimentos de incompletude e insatisfação. Deste modo, o lazer surge como uma compensação às contrariedades do trabalho e, como tal, defende o alargamento do tempo livre e sua utilização mais humanizada. Friedman refere ainda que no caso do "exercício de um trabalho interessante onde a personalidade está empenhada" o lazer assume um caráter de distração em vez de compensação (Friedman, 1961 citado por Dumazedier, 1962, pp. 79-80).

A partir dos anos 50 o lazer posiciona-se então como campo de estudo autónomo e destaca-se relativamente à sociologia do trabalho dando origem à "sociologia do lazer propriamente dita" onde este é tratado como "um produto determinado pelo desenvolvimento industrial e técnico que se traduz em alterações nos modos de vida (aumento de tempo livre, vida urbana, aumento do nível de vida, extensão dos bens de conforto, etc.)" (Lanfant, 1972, p. 209). A este respeito, Sue (1982) considera que é do trabalho que resulta a sensação de tempo livre e que a valorização deste se verifica através das práticas de lazer, formas de emancipação humana e de valorização das relações sociais.

O lazer passou então a exercer uma força de atração crescente através da variedade de atividades que proporciona (Dumazedier, 1974). A partir desta ideia, surge a perspetiva de que o lazer representa uma necessidade social do indivíduo em dispor 
de si para si mesmo, onde a realização pessoal passou a ser possível através da utilização do tempo verdadeiramente livre com práticas relacionadas com o lazer. De acordo com este autor, o lazer consiste então no conjunto de ocupações às quais o indivíduo se dedica de um modo voluntário, seja para descansar, seja para se divertir, seja para desenvolver a sua formação desinteressada, a sua participação social voluntária, liberto das suas obrigações profissionais, familiares e sociais, envolvo de caráter libertador, gratuito (sem obrigação), hedonístico e pessoal (Dumazedier, 1962). São então quatro as características principais do lazer: i) caráter livre - resulta de uma livre escolha, liberta das obrigações impostas pela sociedade; ii) caráter desinteressado - na medida em que o lazer não está necessariamente submetido ao lucro, nem a obrigações domésticas, nem a qualquer outro princípio ideológico (políticos ou espirituais, por exemplo); iii) caráter hedonístico - encarado através de uma perspetiva positiva no que diz respeito às necessidades individuais; iv) caráter pessoal - lazer como forma para satisfazer as necessidades do indivíduo, como libertação pessoal das obrigações impostas pela sociedade. Esta perspetiva foi reforçada por outros autores, como por exemplo Lanfant $(1972$, p. 22) que defendeu o lazer como um conjunto de atividades que se instauram no tempo livre, "sendo este delimitado a partir do tempo de trabalho, isto é, definido como valor económico determinado pelo estado das forças produtivas e pelos modos de distribuição do produto social", ou Stebbins (2005) que afirma que o lazer "é uma atividade não coerciva efetuada durante um período de tempo livre, sendo algo que a pessoa quer fazer, procurando a satisfação pessoal ao usar as suas capacidades e recursos, e é bem-sucedida ao fazê-lo" (Stebbins, 2005 citado por Santos \& Moreira, 2008, p. 250).

Bacal (2003) resume os três elementos que influenciaram o lazer e o seu papel na sociedade atual: o processo de urbanização; a industrialização e a comunicação massificada. O processo de urbanização influenciou as atividades no tempo livre através das alterações na organização estrutural do meio urbano, determinando alterações nos tipos de construções, na ocupação das áreas urbanas e nos serviços de transporte associados. A deslocação das populações para as cidades influenciou o modo como o espaço passou a ser ocupado ou utilizado, podendo ser identificadas duas frações distintas: uma destinada ao exercício das atividades industriais e para 
industriais e, outra, reservada às residências, em muitas das quais se pode observar uma área destinada ao lazer (Bacal, 2003).

\section{Evolução histórica das deslocações motivadas pelos} negócios

Se, por um lado, aquilo que hoje designamos de Turismo de Negócios é visto como um fenómeno da sociedade moderna, por outro, é bem evidente que as deslocações motivadas pelos negócios ou profissões consistem numa das mais antigas formas de viajar (Shone, 1998; Swarbrooke \& Horner, 2001; Horner \& Swarbrooke, 2007;Spiller, 2002; Davidson \& Cope, 2003; Rogers, 2008).

Após o desenvolvimento da agricultura para além de níveis de subsistência em áreas geográficas como África, Ásia e Europa, as comunidades para além de produzir começaram também a usar os produtos agrícolas em trocas por outros produtos que não existiam nas suas regiões, originando o desenvolvimento de mercados de troca, que, por sua vez, impulsionaram o desenvolvimento das comunidades urbanas através da produção e procura de novos produtos (Swarbrooke \& Horner, 2001). O surgimento de grandes impérios como Egito, Pérsia, Grécia e Roma contribuíram ainda mais para o desenvolvimento das deslocações impulsionadas pelos sistemas de trocas predominantes, através da implementação de rotas que serviam para levar bens essenciais a todos os locais geográficos, impulsionando também o desenvolvimento das cidades, locais de eleição para as atividades de comércio e a interação humana ${ }^{1}$ (Gartrell, 1992 citado por Spiller, 2002).

Uma das rotas comerciais mais importantes consistiu precisamente na antiga Rota da Seda $^{2}$, atingindo o seu auge na Idade Média e através da qual uma grande variedade de bens era transportada da Ásia para a Europa e vice-versa (para além de bens

\footnotetext{
${ }^{1}$ A título de exemplo, na Roma antiga, o Forum Romano consistia no principal espaço social e comercial localizado no centro da cidade. Composto por vários edifícios e estruturas, consistia no centro nevrálgico de toda a atividade comercial e no espaço próprio para a realização de discussões públicas, resolução de questões judiciais e de outros assuntos de interesse público (Spiller, 2002).

${ }^{2}$ Existe atualmente um programa de revalorização turística desta rota promovido pela UNWTO: http://silkroad.unwto.org/en, consultado em 15/09/2012.
} 
materiais, originou a troca de culturas, religiões, etc.). Esta rota, que na verdade consistia num conjunto de várias rotas interligadas, percorria milhares de quilómetros e foi usada durante vários séculos, originando o surgimento de inúmeras infraestruturas e serviços de apoio que iam ao encontro das necessidades dos viajantes dessa altura, como por exemplo, locais de refeições e repouso para viajantes e animais de transporte ou serviços de apoio relacionados com a organização de viagens em grupo de modo a tornarem os percursos mais seguros. $\mathrm{O}$ desenvolvimento de toda esta atividade económica impulsionou também o desenvolvimento de importantes cidades ao longo do percurso, como é o caso de Constantinopla (atual Istambul) (Shone, 1998; Swarbrooke \& Horner, 2001).

Durante o período medieval, o mercado de troca estava solidamente implementado na Europa e, como tal, potenciava-se o desenvolvimento das feiras comerciais que eram estruturadas fisicamente nas principais cidades e onde acorriam comerciantes de todas as partes. Foi a partir do século XII que este tipo espaços de negócio mais se desenvolveram, especialmente em países como França (onde a região de Champagne assumiu um importante papel), Holanda, Bélgica, Alemanha, Suíça, Espanha e Itália. Entre 1320 e 1464, Genebra era considerada a maior cidade comercial da Europa (UFI, $2011^{3}$ ). Em meados do século XV surgiu uma das mais famosas feiras comerciais da época. A feira anual Beaucaire, que se realizava nas margens do rio Rhône, no Sul de França, era conhecida em todo o Mundo Ocidental (Horner \& Swarbooke, 2007). Devido à grande dimensão destas feiras (que duravam geralmente vários dias) verificava-se a permanência dos comerciantes por vários dias, usufruindo dos serviços locais existentes, como alojamento e alimentação, entre outros.

Com a Era dos Descobrimentos surgiram também novas rotas comerciais, nomeadamente a Rota das Especiarias que se desenvolveu a partir da descoberta do caminho marítimo para a Índia, contribuindo para o impulso do mercantilismo na Europa. A pirataria (Inglesa, Holandesa, Francesa, entre outras), apesar de ilícita, não deixa de representar uma forma de atividade ligada ao negócio, com fortes impactos na atividade mercantil da época. Também a colonização, a disseminação da religião, as

\footnotetext{
3 http://www.ufi.org/Public/Default.aspx?Clef_SITESMAPS=105\&Clef_SITESMAPS=106\&Clef_SITESMAPS=108, consultado em 20/08/2012.
} 
expedições científicas, a procura de trabalho ou de negócio noutras regiões (como por exemplo, os fluxos migratórios despoletados pelas Corridas do Ouro do século XIX) podem ser apresentadas, entre outras, como formas de viajar motivadas pelos negócios ou profissões.

A partir do início da industrialização as viagens motivadas pelo negócio e as profissões aumentaram significativamente, principalmente na Europa. Entre 1750 e 1900 três razões principais levaram a esse aumento (Swarbrooke \& Horner, 2001): i) a Revolução Industrial, que teve o seu início no Reino Unido e rapidamente se propagou ao resto da Europa, originando um aumento substancial da produção de bens que tinham que ser comercializados, divulgados e transportados. Para levar a cabo essa tarefa de comercializar, divulgar e transportar surgiu a função de vendedor, que implica viajar frequentemente em trabalho; ii) a colonização em África, Médio Oriente e Ásia, por muitos países europeus, que originou a necessidade de deslocar pessoas e bens para os países colonizados; iii) o desenvolvimento do automóvel e respetivas vias rodoviárias e o desenvolvimento do transporte ferroviário, que vieram possibilitar um aumento das deslocações para locais mais distantes e de uma forma mais rápida e frequente.

Com o início do século $X X$, iniciou-se também uma nova era nas viagens de negócios, mais precisamente com origem nos Estados Unidos onde os conceitos de conferência ou convenção começaram a surgir com cada vez mais frequência. Associações industriais, comerciais e científicas, juntamente com entidades políticas, começaram a organizar encontros em grande escala nos finais do século XIX que se desenvolveram nas primeiras décadas do século XX. O desenvolvimento deste tipo de eventos despertou a atenção dos potenciais destinos, capazes de albergar tais encontros, para os benefícios económicos e sociais que representavam. Consequentemente, as cidades começaram a promover os seus recursos e atrativos de forma a captar o maior número possível de eventos, verificando-se o surgimento de organizações especializadas neste domínio: os Convention Bureaux (por vezes também designados de Convention \& Visitors Bureaux). O primeiro surgiu em Detroit em 1896, seguido de Cleveland (1904), Atlantic City (1908), Denver e St. Louis (1909) e Louisville e Los Angeles (1910) (Spiller, 2002; Gartrell, 1994; Swarbrooke \& Horner, 2001; Rogers, 2008). A proliferação destas 
estruturas organizativas nos Estados Unidos levou à criação da International Association of Comvention Bureaux ${ }^{4}$ (IACB) em 1914 com o intuito de proporcionar a troca de informação e conhecimento entre os seus membros de modo a tornar esta atividade económica mais forte e profissionalizada. O interesse crescente na captação de um maior número de visitantes, para além da captação de eventos relacionados com os negócios, levou a que em 1974 esta organização se passasse a designar de International Association of Convention and Visitors Bureaux ${ }^{5}$ (IACVB) (Schweitzer, 1997 citado por Spiller, 2002).

Por esta altura surgia então um novo paradigma associado às deslocações motivadas pelos negócios ou profissões: as cidades, regiões e países (i.e. destinos) começavam a competir para atrair o maior número de eventos de negócios e de visitantes, através da promoção dos seus recursos e atrativos. É, provavelmente, a partir desta altura que se começa a desenvolver em maior escala aquilo a que hoje designamos de Turismo de Negócios ou Meetings Industry, onde as atividades ligadas à cultura, entretenimento e lazer têm um importante papel durante a permanência dos visitantes. Na Europa, a Belle Epoque (que despoletou nos finais do século XIX e durou até à eclosão da I Guerra Mundial em 1914) veio originar um conjunto de novas transformações nas sociedades, a nível cultural, tecnológico e social. Esta nova época, associada ao espetáculo, ao divertimento, às expressões artísticas, proporcionou não só novas formas de lazer e entretenimento (quer para os residentes, quer para os visitantes), mas também de negócio e de atividades profissionais (como por exemplo, ligadas ao cinema, aos cabarés, aos espetáculos).

Na primeira metade do século XX as duas Guerras Mundiais vieram travar o rápido crescimento das viagens de negócios na Europa. No entanto, e à semelhança do que se verificou com o turismo em geral, o grande boom das viagens e do turismo de negócios surgiu após o final da Segunda Guerra Mundial, impulsionado fortemente pelo desenvolvimento da aviação comercial (Shone, 1998) e coincidindo com o início da época a que Fourastié (1979) designou de "trinta anos gloriosos", caraterizada pela prosperidade económica e por um consumo fordista massificado sustentado no pleno

\footnotetext{
${ }^{4}$ Cuja tradução é "Associação Internacional de Convention Bureaux".

${ }^{5}$ Verificando-se a introdução do termo visitors, que significa "visitantes".
} 
emprego e no estado providência, originando aquilo a que alguns autores se referem como sociedade de consumo (Braudillard, 1970) ou da abundância (Galbraith, 1958). Como refere Santos (2011, p. 84), "como o emprego é a fonte de rendimento necessária para dar significado a outros valores, sabe-se que a atuação das pessoas tem uma relação obrigatoriamente próxima com a produção." Maior consumo significa maior produção (e vice-versa), o que representa um maior volume de atividades profissionais e, consequentemente, mais deslocações motivadas pelos negócios.

Alguns autores (Horner \& Swarbrooke, 2007; Swarbrooke \& Horner, 2001; Lawson, 2000) identificam um conjunto de fatores que originaram o desenvolvimento das viagens de negócios no pós-guerra: i) o avanço tecnológico nos transportes; ii) a ascensão da economia global; iii) a redução dos obstáculos à livre comercialização através do surgimento de blocos comerciais transnacionais, como a União Europeia e a North American Free Trade Agreement ${ }^{6}$ (NAFTA); iv) o desenvolvimento das capacidades de comunicação através do aumento das competências linguísticas das populações (maior nível de formação e educação); v) o crescimento de associações profissionais, comerciais ou outras, com interesses comuns e que proporcionam a realização de reuniões ou outros eventos; vi) a relativa paz mundial, que propicia maior vontade e segurança para viajar; vii) o crescimento de novas indústrias relacionadas com a informação e tecnologia, que impulsionam deslocações para comercializar novos produtos e prestar assistência a clientes; viii) o grande crescimento demográfico no mundo; xix) os esforços encetados pelos governos no sentido de atrair turistas de negócios com elevado poder de compra; e x) o desenvolvimento de novas formas de viagens e turismo, associadas aos negócios e profissões, como por exemplo as viagens de incentivo ou o lançamento de produtos. Alguns destes fatores relacionam-se, direta ou indiretamente, com um conjunto de transformações económicas e políticas que ocorreram neste período e que de influenciaram o desenvolvimento económico, científico, tecnológico e social, principalmente na Europa: a implementação do Plano Marshall; a criação da Organização para a Cooperação e Desenvolvimento Económico $\left(\mathrm{OCDE}^{7}\right)$; a criação da

\footnotetext{
${ }^{6}$ Cuja tradução é "Tratado Norte-Americano de Livre Comércio" e inclui Estados unidos da América, Canadá e México.

${ }^{7}$ Teve origem em 1948 e era inicialmente designada por “Organização para a Cooperação Económica (OECE)"
} 
Organização do Tratado do Atlântico Norte $\left(\mathrm{OTAN}^{8}\right)$; e a assinatura do Pacto de Varsóvia.

A segunda metade do século XX corresponde a um período marcado fortemente pelo aumento na procura de reuniões e outros eventos de negócios, evidenciando ainda mais o potencial económico que este setor representa para os destinos que, por sua vez, começam a investir fortemente na criação de infraestruturas específicas e de apoio e na promoção dos seus recursos e atributos (Lawson, 2000). O progressivo aumento no investimento em infraestruturas especificamente vocacionadas para os eventos de negócios verificou-se principalmente a partir da década de 60 (Rogers, 2008; Shone, 1998) e atingiu o seu auge na década de 90 (Rogers, 2008). Todavia, ainda na atualidade são feitos avultados investimentos em infraestruturas para especificamente para a Meetings Industry. Embora numa escala relativamente mais reduzida em comparação com outros destinos, podemos dar o exemplo do investimento que está a ser feito com a construção do Centro de Convenções e Espaço Cultural do Convento de S. Francisco, em Coimbra, resultante da recuperação e reconversão do antigo Convento de S. Francisco. O projeto prevê a construção de um grande auditório com cerca de 1.147 lugares, a recuperação do mosteiro, a construção de uma praça pedonal a implementar numa área de $27.499 \mathrm{~m}^{2}$, de um parque de estacionamento sob a praça, com quatro pisos e capacidade para 557 lugares, e de um restaurante ${ }^{9}$.

Por outro lado, é bem evidente a grande importância que a evolução do transporte aéreo teve para o desenvolvimento das viagens de negócios e para a formação da figura do Homem de Negócios. Para além do desenvolvimento tecnológico (maiores aviões, mais rápidos, mais seguros, etc.), a desregulamentação do transporte aéreo na década de 70 abriu novos mercados que, por sua vez, originaram uma maior discriminação do fator preço. Em 1978, a companhia aérea norte americana Pam Am tornou-se a primeira no mundo a introduzir a classe executiva (business class), situando-a entre classe económica e primeira classe (Bowen, 2010). Poucos meses depois esta tendência já tinha sido seguida por muitas outras companhias aéreas

\footnotetext{
${ }^{8}$ Traduzido do inglês "North Atlantic Treaty Organization (NATO)".

${ }^{9}$ http://www.cm-coimbra.pt/index.php?option=com_content\&task=view\&id=1315\&ltemid=573, consultado em 16/09/2012.
} 
(Gimes, 1980 citado por Bowen, 2010). Atualmente, a classe executiva é associada a um nível de qualidade elevado, incluindo geralmente algumas características diferenciadoras, tais como: i) maior flexibilização na marcação/alteração da viagem (possibilidade de alterações de última hora sem custos adicionais, menos restrições no transporte de bagagem, etc.); ii) maior conforto e melhores comodidades durante o voo (lugares mais espaçosos, melhores refeições, fontes de energia individualizadas para ligação de computadores portáteis, etc.); iii) ambiente propício à realização de negócios (business-friendly environment) entre o check-in e o embarque (lounges com acesso à internet, salas de reuniões, etc.) (Derudder et al., 2010). Em contrapartida, os atentados terroristas do 11 de setembro em 2001 representam um marco importante no desenvolvimento do transporte aéreo e também na evolução do Turismo de Negócios, representando significativas quebras económicas em ambos os casos devido à insegurança e medo que se instalaram nos tempos que se seguiram e que mais tarde se alastraram a outros meios de transporte (devido aos atentados terroristas de $11 \mathrm{de}$ março de 2004 no terminal ferroviários de Atocha, em Madrid) (Boniface \& Cooper, 2005).

Mas não só no transporte aéreo se verificaram importantes mudanças. A abertura do túnel do Canal da Mancha em 1994 (Eurotúnel), o desenvolvimento do transporte ferroviário de alta velocidade, a abolição das fronteiras no espaço europeu e a introdução da Moeda Única (Euro) vieram impulsionar ainda mais as deslocações em negócios (Boniface \& Cooper, 2005).

\section{Definições do Turismo de Negócios}

A revisão bibliográfica permite constatar, por um lado, a insuficiente literatura e investigação académica existentes na área específica do Turismo de Negócios que, apesar de tudo, nos últimos anos, tem sido alvo de maior atenção. Por outro lado, a falta de terminologia estandardizada que se traduz na inexistência de dados estatísticos suficientes para caracterizar de um modo holístico o peso e a representatividade do setor (Weber \& Chon, 2002; Davidson \& Cope, 2003; 
Swarbrooke \& Horner, 2001; UNWTO, 2006; Rogers, 2008) é também um handicap importante.

Em 1991, a Organização Mundial de Turismo (OMT) deu um dos primeiros passos para o esclarecimento e reconhecimento das deslocações motivadas pelos negócios e profissões definindo turismo como: "as atividades desenvolvidas por indivíduos (visitantes) no decurso das suas viagens e estadas para e em locais situados fora do seu ambiente habitual por um período consecutivo que não ultrapasse um ano para fins recreativos, de negócios e outros." (OMT, 1991 in Cunha, 2006, p. 20). Em 1995, a OMT estabelece, inclusivamente, a categoria de "negócios e motivos profissionais" na sua forma de classificação do turismo através da motivação principal da viagem (OMT, 1995).

Cunha (2006) citando Vellas (s.d.) define o Turismo de Negócios como o "conjunto de viagens realizadas no âmbito de atividades profissionais qualquer que seja a sua natureza: económica, científica, política e social" (Cunha, 2006, p. 231). O mesmo autor (Cunha, 2003, pp. 51-52) salienta a importância económica deste setor ao referir que "os negócios e as profissões têm como consequência a deslocação de grande número de pessoas dando origem a importantes movimentos turísticos de grande significado económico. Por razões ligadas aos negócios e ao exercício de profissões as pessoas deslocam-se para participar em reuniões, congressos, missões, exposições, feiras, para estabelecer contactos com empresas ou realizar negócios (...). Os destinos privilegiados são os que dispõem de centros de congressos e exposições e os grandes centros urbanos ou industriais." Estes centros apresentam vantagens imediatas ao nível do aumento do consumo e da redução da sazonalidade da visitação. Todas as atividades de turismo (alojamento, restauração e transporte) e as de lazer local beneficiam claramente da presença de um número significativo de visitantes que para além de outras características têm, normalmente, mais dinheiro disponível que outros turistas, devido às economias de escala que as representações implicam.

Para além de um maior gasto geralmente associado ao turista de negócios, podemos encarar também a sua importância económica através da rentabilização de espaços e da atenuação da sazonalidade que este segmento proporciona nos destinos, daí a sua grande importância estratégica. A isto se junta um perfil que pelo nível de informação 
elevada, rendimento acima da média, boas habilitações literárias e procura de cultura/lazer diversificada, resulta num incremento significativo dos níveis de despesa fruto da atividade económica local.

\subsection{Subsetores do Turismo de Negócios}

O Turismo de Negócios é um conceito "chapéu" que abrange, para além das atividades e serviços inerentes ao turismo em geral, um variado leque de eventos ou atividades mais específicas a realizar no destino. A grande heterogeneidade de conceitos e falta de terminologia estandardizada constata-se através de vários acrónimos utilizados ao longo dos últimos tempos para definir os respetivos eventos. Referimo-nos a MECE (Meetings, Events, Conventions, Exhibitions ${ }^{10}$ ), a MCE (Meetings, Conventions, Exhibitions ${ }^{11}$ ), a CEMI (Conventions, Exhibitions, Meetings, Incentives ${ }^{12}$ ), a MC\&IT (Meetings, Conventions and Incentive Travel ${ }^{13}$ ) ou, o mais utilizado internacionalmente, a MICE (Meetings, Incentives, Conventions, Exhibitions ${ }^{14}$ ) (Weber \& Chon, 2002; Rogers, 2008).

Como tentativa de uniformização de conceitos e criação de uma imagem mais forte do setor surgiu, em 2006, o conceito de Meetings Industry (MI), cuja tradução à letra é "indústria das reuniões". Este conceito veio substituir, de um modo geral, a utilização da expressão MICE (e outras expressões similares) e começou a ser utilizado em novembro desse ano, de acordo com uma decisão levada a cabo pela International Congress \& Convention Association (ICCA), a Meeting Professionals International (MPI), a Reeds Travel Exhibitions e a United Nations World Tourism Organization (UNWTO).

Segundo a definição apresentada, a Meetings Industry inclui: atividades baseadas na organização, promoção, venda e entrega de reuniões e eventos; produtos e serviços que incluem reuniões empresariais, associativas e governamentais, incentivos

\footnotetext{
${ }^{10}$ Reuniões, Eventos, Convenções, Exposições.

${ }^{11}$ Reuniões, Convenções, Exposições.

${ }^{12}$ Convenções, Exposições, Reuniões, Incentivos.

${ }^{13}$ Reuniões, Convenções e Viagens de Incentivo.

${ }^{14}$ Reuniões, Incentivos, Convenções, Exposições.
} 
empresariais, seminários, congressos, conferências, convenções, exposições e feiras (WNWTO, 2006).

De acordo com vários autores (Shone, 1998; Swarbrooke \& Horner, 2001; Davidson \& Cope, 2003; Cunha, 2006; Rogers, 2008), podemos considerar que o Turismo de Negócios se divide em duas vertentes: uma vertente individual, constituída pelos indivíduos que viajam frequentemente devido às suas obrigações profissionais; e uma vertente grupal ou coletiva onde podemos incluir eventos como viagens de incentivo, congressos ou convenções, feiras ou exposições e eventos corporativos, e que surge frequentemente associada ao conceito de Meetings Industry.

Deste modo, podemos considerar que o Turismo de Negócios se divide nestas duas componentes: individual (viagens de negócios individuais); e coletiva (Meetings Industry: reuniões ${ }^{15}$, exposições/feiras, incentivos, hospitalidade corporativa) (Figura 1). Se bem que esta última tenha um muito maior impacto na atividade económica local, a orientação que queremos dar a este texto obriga a que as viagens de negócios individuais sejam também valorizadas já que em algumas épocas do ano são fundamentais para o aumento da taxa de ocupação da hotelaria.

Figura 1: Estrutura do Turismo de Negócios

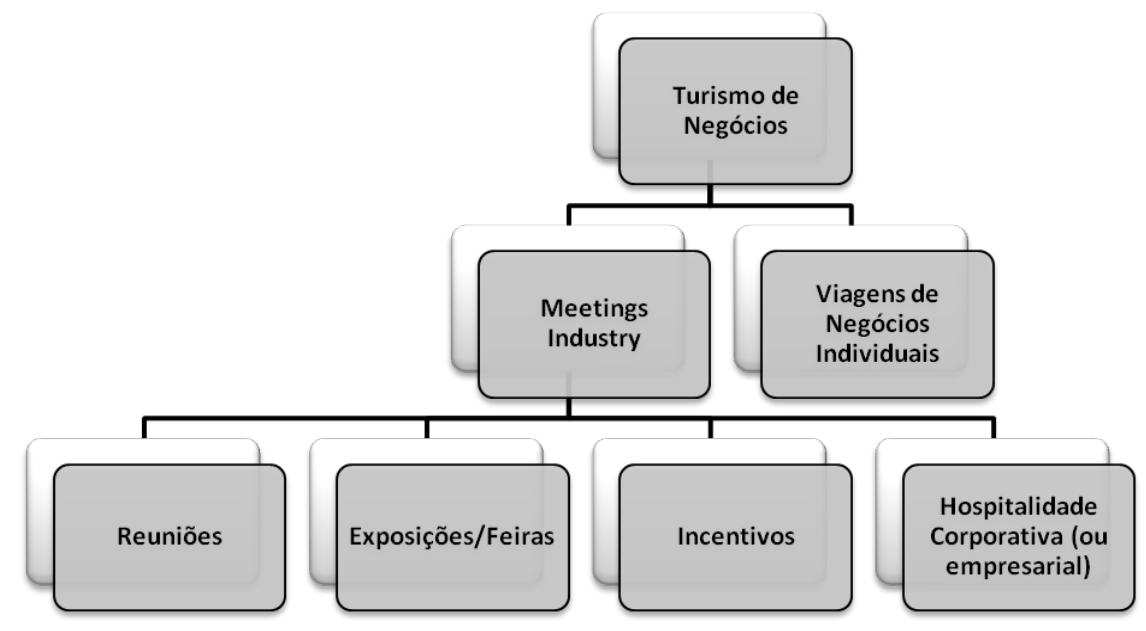

(Fonte: Elaboração própria, com base em Davidson \& Cope (2003) e Rogers (2008))

\footnotetext{
${ }^{15}$ No conceito de "reuniões" podemos incluir desde reuniões entre pequenos grupos de pessoas a grandes eventos como conferências, congressos ou convenções. As reuniões podem ser classificadas de acordo com vários critérios, como o tamanho, o objetivo específico ou o tipo de pessoas que as frequentam. No entanto, o mais utilizado é o tipo de comprador envolvido, ou seja, quem promove e organiza a reunião. Neste caso, podemos ter compradores associativos, corporativos, órgãos de governo, estruturas intergovernamentais, grupos religiosos ou agências sindicais. Os dois principais segmentos são o segmento corporativo e o segmento associativo, que representam a maior parte da procura total (Davidson \& Cope, 2003)
} 
Apesar da grande importância da vertente individual para o aumento das taxas de ocupação hoteleira ao longo do ano e para o desenvolvimento das economias dos destinos, é na vertente grupal ou coletiva que reside o principal foco das estratégias de marketing e promoção por parte dos destinos (Swarbrooke \& Horner, 2001; Cunha, 2006; Davidson \& Cope, 2003; Rogers, 2008; UNWTO, 2006). Importa realçar também que, devido à sua maior representatividade, é precisamente o segmento das "reuniões" que tem sido o principal alvo de estudos e análises estatísticas, apesar de muitas vezes não existir consistência na caracterização do tamanho e tipologia das reuniões (UNWTO, 2006).

\section{Tendências e perspetivas de futuro no Turismo de} Negócios

Como qualquer outro setor de atividade ou segmento turístico, o Turismo de Negócios é influenciado direta e indiretamente pela conjuntura económica global. No entanto, quando comparado com o Turismo de Lazer, apresenta uma maior resiliência e estabilidade em tempos de crise (Duffy \& McEuen, 2010; Rogers, 2008; Davidson \& Cope, 2003). Se, por um lado, as dificuldades económicas levam à redução dos gastos relacionados com a organização e participação em eventos de negócios, por outro, é nos períodos mais difíceis que muitas empresas decidem planear e organizar reuniões, conferências, workshops ou viagens de incentivo (entre outros tipos de eventos) de forma a contribuir para a revitalização dos negócios e motivação das suas equipas.

Para além da crise económica despoletada em 2008, nos últimos anos verificaram-se outras situações muito graves cujas repercussões se verificaram não só no Turismo de Negócios mas também nas restantes formas de turismo, como por exemplo: i) ações terroristas, como os atentados de 11 de setembro de 2001 às torres gémeas do World Trade Center em Nova lorque, os atentados de 2002 em Bali na Indonésia, os atentados de 2005 em Madrid, os atentados no Metro de Londres em 2005, os atentados no Egito em 2005 e 2006, os atentados na Índia em 2011, entre outros; ii) epidemias e desastres naturais, como é o caso do surto da Síndrome Respiratória Aguda Severa, conhecida como pneumonia atípica ou asiática ou SARS que surgiu em 
2003, o surto de gripe das aves ou H5N1 que surgiu em 2005, o tsunami que em 2004 abalou o Sudoeste Asiático, o furacão Katrina que em 2005 devastou várias cidades dos Estados Unidos da América, o tsunami que em 2011 assolou o Japão, entre outros; iii) revoluções e guerras, como por exemplo, a primavera Árabe, designação dada aos protestos e revoluções que têm ocorrido em vários países árabes desde finais de 2010. Todos estes acontecimentos originaram fortes impactos negativos no turismo dos respetivos destinos. Paradoxalmente, e apesar de tudo, estes acontecimentos podem estimular também a procura por reuniões, ações de formação e conferências internacionais relacionadas com gestão de crises, apoio e auxílio às comunidades locais, entre outros motivos (Rogers, 2008).

Também os avanços tecnológicos têm afetado o Turismo de Negócios de certa forma. O desenvolvimento das comunicações via satélite veio permitir a realização de eventos à distância através de videoconferências, utilizando ferramentas de comunicação sem custos ou com custos muito reduzidos, como é o caso do Skype ou do Voip. Por outro lado, o desenvolvimento tecnológico veio permitir aumentar a qualidade no planeamento, organização e realização dos eventos possibilitando, por exemplo, a divulgação dos eventos e inscrição nos mesmos através da Internet, disponibilizando acesso à Internet sem fios durante o evento ou permitindo a tradução simultânea em eventos internacionais. Segundo Rogers (2008), os diversos espaços para eventos de negócios têm investido na instalação de equipamentos tecnológicos que lhes permitam adaptar-se a estas novas tendências do mercado.

Apesar dos constantes avanços tecnológicos e do aumento do número de reuniões e conferências realizadas à distância, a necessidade de realizar reuniões frente a frente (face-to-face meetings) tende a predominar devido ao caráter de socialização, fortalecimento relacional, rutura com o quotidiano e oportunidades de atividades de lazer e recreio que representam para os participantes (Graham in Beaverstock et al., 2010; Rogers, 2008; Davidson, 2008; Ladkin in Buhalis e Costa, 2006). 


\section{Considerações finais}

Os conceitos de trabalho, tempo livre e lazer foram-se moldando ao longo dos tempos, quer na sua forma, quer na sua valoração pelas sociedades. Não só se assistiu a uma valoração dos tempos, espaços e práticas de lazer, como também se verificou o mesmo relativamente ao trabalho. O desenvolvimento das economias e o fenómeno da globalização impulsionou as viagens relacionadas com os negócios e o trabalho, dando origem ao fenómeno que hoje entendemos como Turismo de Negócios. Se, por um lado, podemos entender as atividades relacionadas com o lazer como um setor que implica o desenvolvimento de negócios (venda de viagens, alojamento, entretenimento animação turística, etc.), por outro, o Turismo de Negócios implica também, e necessariamente, o desenvolvimento de atividades de lazer (programas de lazer associados a congressos ou outros eventos, viagens de incentivo, etc.). Por isso, é visto como um segmento turístico com grande potencial de desenvolvimento. A baixa sazonalidade, o impacto ambiental controlado, a possibilidade de rentabilização de salas e outros espaços, a grande ocupação de alojamento, os acréscimos significativos no consumo de alimentação e bebidas (almoços, jantares de gala, coffee breaks), a potenciação das atividades de lazer nos territórios de referência e a relativa resistência à crise económica atual, são alguns dos fatores que tornam o Turismo de Negócios um produto turístico tão atrativo para os destinos. Constitui-se como uma das mais importantes vertentes de segmentação do mercado turístico, dinamizadora de variadas atividades que englobam desde as estruturas e equipamentos específicos (fatores de suporte), como centros de congressos e exposições, até às atividades complementares relacionadas com os transportes, restauração, hotelaria, animação cultural e desportiva, pequeno e grande comércio, entre outras. Por isso, não será de estranhar a crescente atenção que os vários agentes dos destinos (públicos e privados) têm dedicado a este mercado, até porque este segmento está muito associado aos processos de gestão do destino e desenvolvimento, planeamento e definição das políticas do destino turístico e isso torna a sua presença um fator de competitividade e sustentabilidade. 


\section{Menção de apoio}

Este trabalho conta com o apoio financeiro da Fundação para a Ciência e a Tecnologia através de uma Bolsa de Doutoramento (SFRH/BD/68804/2010) financiada pelo POPH - QREN - Tipologia 4.1 - Formação Avançada e comparticipada pelo Fundo Social Europeu.
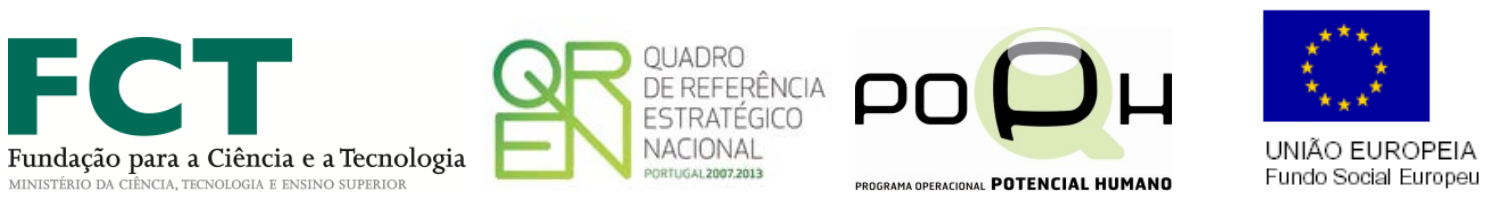

\section{Bibliografia}

Bacal, S. (2003). Lazer e o Universo dos Possíveis. São Paulo. Editora Aleph.

Boniface, B. \& Cooper, C. (2005). Worldwide Destinations: The geography of travel and tourism (4th Ed.). Oxford. Elsevier.

Bowen, J. (2010). A People Set Apart: The Spatial Development of Airline Business Class services in Beaverstock et al. (ed.). International Business Travel in the Global Economy. Surrey. Ashgate, pp.11-30.

Braudillard, J. (1979). A Sociedade de consumo. Lisboa. edições 70.

Cunha, L. (2006). Economia e Política do Turismo. Lisboa. Editorial Verbo.

Cunha, L. (2003). Introdução ao Turismo (2a ed.). Lisboa. Editorial Verbo.

Davidson, R. (2008). University Education for the Meetings Industry in López, D. (Ed.).

Turismo de Negocios y Reuniones. Convenciones, Congresos e Incentivos. Valencia. Tirant lo Blanch. pp. 15-24.

Davidson, R. \& Cope, B., (2003). Business Travel. Conferences, Incentive Travel, Exhibitions, Corporate Hospitality and Corporate Travel. Harlow. Pearson Education Limited. 
Derudder et al. (2010). Geographies of Business Air Travel in Europe in Beaverstock et al. (ed.). International Business Travel in the Global Economy, Surrey. Ashgate. pp. 3156.

Duffy, C., \& McEuen, M. (2010). The Future of Meetings: The Case for Face-to-Face, Cornell Hospitality Industry Perspectives. №. 6. setembro 2010. Nova lorque. The Maritz Institute.

Dumazedier, J. (1962). Vers une civilisation du loisir? Paris. Éditions Seuil.

Dumazedier, J. (1974). Sociologie Empirique du Loisir, Critique et Contre Critique de la civilisation du loisir. Paris. Éditions Seuil.

Dumazedier, J. (2002). Lazer: valores residuais ou existenciais? In Poirier, J. (Dir.). História dos Costumes, Éticas e Estéticas. Lisboa. Editorial Estampa. pp. 147-221.

Fourastié, J. (1979). Les Trente Glorieuses, ou la Révolution invisible de 1946 à 1975. Paris, Fayard.

Galbraith, J. (1958). The Affluent Society. Nova lorque. Mariner Books.

Gama, A. (2008a). Fundamentos para uma geografia do tempo livre in Gama, A. \& Santos, N. (ed.). Lazer. Da libertação do tempo à conquista das práticas. Coimbra. Imprensa da Universidade de Coimbra. pp. 85-105.

Gama, A. (2008b) Notas para uma Geografia do tempo livre in Gama, A. \& Santos, N. (ed.) Lazer. Da libertação do tempo à conquista das práticas. Coimbra. Imprensa da Universidade de Coimbra. 1a ed. 1988. pp. 17-28.

Gama, A. \& Santos, N. (2008). Tempo livre, lazer e terciário in Gama, A. \& Santos, N. (ed.). Lazer. Da libertação do tempo à conquista das práticas. Coimbra. Imprensa da Universidade de Coimbra. pp. 59-83.

Graham, B. (2010), Foreword: Business Travel in the Global Economy in Beaverstock et al. (Ed.). International Business Travel in the Global Economy. Surrey. Ashgate. pp. xviiXXV.

Horner, S. \& Swarbrooke, J. (2007). Consumer Behavior in Tourism (2nd Ed.). Oxford. Elsevier. 
Ladkin, A. (2006). Conference tourism - MICE market and business tourism in Buhalis, D. e Costa, C. Tourism Frontiers. Consumers, products and industry. Oxford. Elsevier. pp. $57-65$.

Lafargue, P. (1991). O Direito à Preguiça. Lisboa. Editorial Teorema.

Lanfant, M. (1972). Les Théories du Loisir. Lisboa. P.U.F.

Lawson, F. (2000). Congress, convention and exhibition facilities: Planning, design and management. Londres. Architectural Press.

Lipovetsky, G. (2006), A Felicidade Paradoxal. Ensaio sobre a sociedade do hiperconsumo, Lisboa, Edições 70.

Martins, L., (2004). Espaços de Lazer e de Turismo no Noroeste de Portugal. Porto. Edições Afrontamento.

Nazareth, L. (2007). The Leisure Economy: How Changing Demographics, Economics, and Generational Attitudes Will Reshape Our Lives and Our Industries. Ontario. John Wiley \& Sons Canada., Ltd.

Organización Mundial de Turismo (OMT). (1995). Conceptos, definiciones y clasificaciones de las estadísticas de turismo. Manual Técnico № 1. Madrid. OMT.

Rogers, T. (2008). Conferences and Conventions. A Global Industry. 2nd Ed. Oxford. Butterworth-Heinemann

Santos, N. (2011). Lazer tempo livre e novos consumos In Hernâni Veloso Neto e Sandra Lima Coelho (Org.). Novas dimensões do consumo na sociedade contemporânea. Porto. IS-FLUP. pp. 84-97.

Santos, N. \& Moreira, C. (2008). O Lazer e a Noite. Imagens de uma cidade universitária: Coimbra In Santos, N. e Gama, A. Lazer. Da libertação do tempo à conquista das práticas. Coimbra. Imprensa da Universidade. pp. 247-271.

Shone, A. (1998). The Business of Conferences: a hospitality setor overview for the UK and Ireland. Oxford. Butterworth-Heinemann. 
Spiller, J. (2002). History of Convention Tourism in Weber, K. e Chon, K. (ed.). Convention Tourism. International Research and Industry Perspectives. Nova Iorque. The Haworth Hospitality Press. pp.3-19.

Stebbins, R. (2005). Research Reflections: Choice and Experimental Definitions of leisure. Leisure Sciences. № 27: 349-352.

Sue, R. (1982). Vers une société du temps Libre? Sociologie d'Aujourdhui. Paris. P.U.F. Swarbrooke, J. \& Horner, S. (2001). Business Travel and Tourism. Oxford. ButterworthHeinemann.

Touraine, A. (1969). La société post-industrielle. Naissance d'une société. Paris. Denoël Gonthier.

UNWTO (2006). Measuring the Economic Importance of the Meetings Industry Developing a Tourism Satellite Account Extension. Madrid. World Tourism Organization.

Veblen, T. (1965). A Teoria da Classe Ociosa. São Paulo. Livraria Pioneira Editora

Weber, K. \& Chon, K. (Ed.) (2002). Convention Tourism. International Research and Industry Perspetives. Nova lorque. The Haworth Hospitality Press.

Zorrilla Castrejana, R. (1990). El consumo del ocio. Una aproximación a la teoría del tiempo libre desde la perspetiva del consumo. Gobierno Vasco. Servicio Central de Publicaciones. 